\title{
FOSSIL CROCODILE DISCOVERED ALONG THE CARROT RIVER
}

TIM T. TOKARYK, Saskatchewan Museum of Natural History, 2340 Albert Street, Regina, Saskatchewan. S4P 3V7

In September 1991, Dr. Steve Cumbaa of the Canadian Museum of Nature in Ottawa and I began prospecting for fossils along the Carrot River, northeast of Melfort, Saskatchewan. Our intentions were to explore known localities as well as virgin territory. Dr. Cumbaa is interested in fossil fish so we paid close attention to the shale surfaces that contained these fossils. Upon visiting a site first discovered by museum staff in 1959, we found large bones high up on the vertical face of the riverbank. Our immediate plans did not include major excavation so it was decided to continue prospecting and hope that I could return soon to collect whatever was still encased in the rock.

The fossils were precariously perched on the edge of the riverbank, five metres above the river. Because spring runoff increased the volume of water in the river considerably, there was serious concern that undercutting and general erosion could destroy the bones by the next year. We had to get the skeleton out soon. Thanks to the Saskatchewan

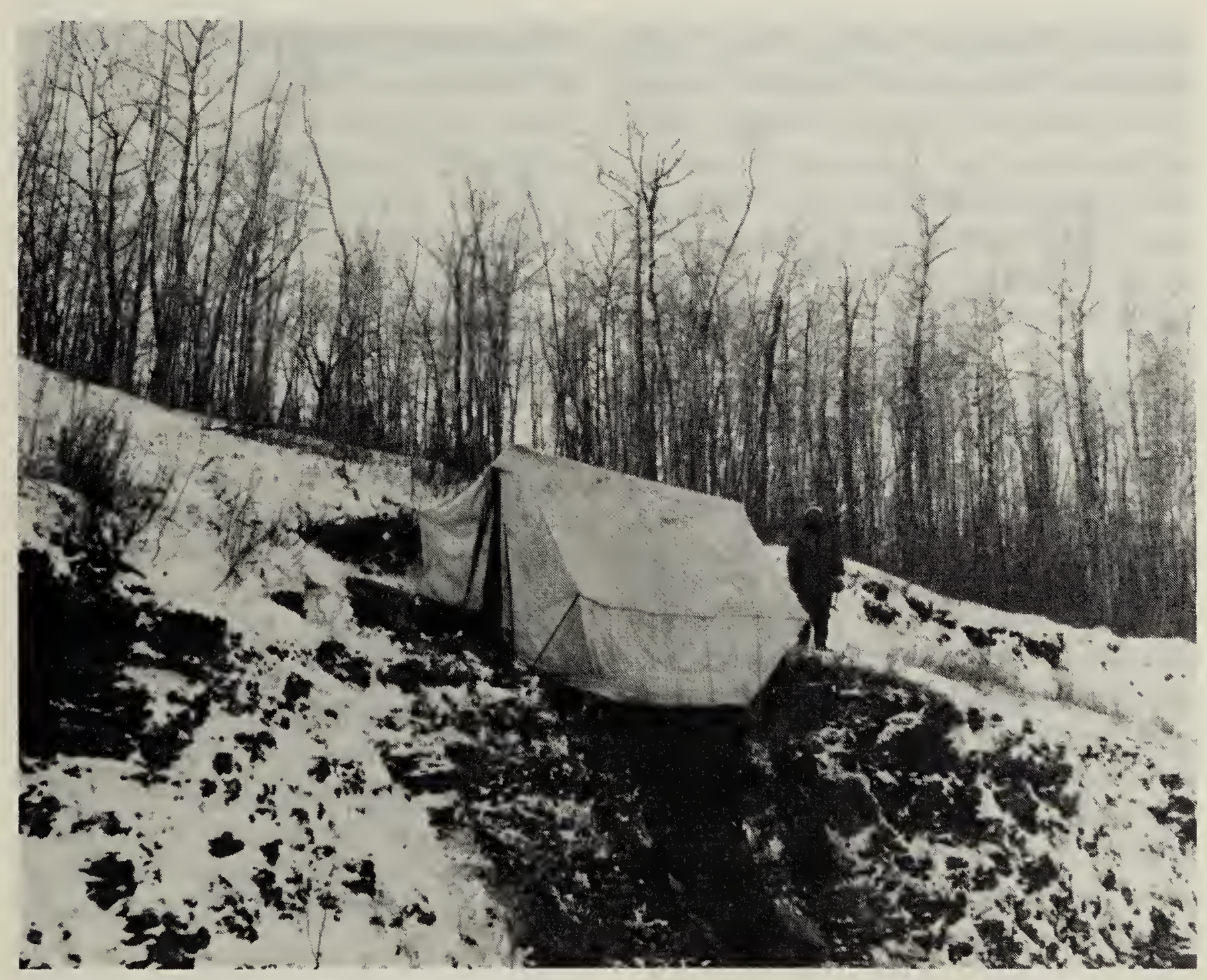

The cutbank of the Carrot River. Tent encloses the specimen.

Tim Tokaryk 


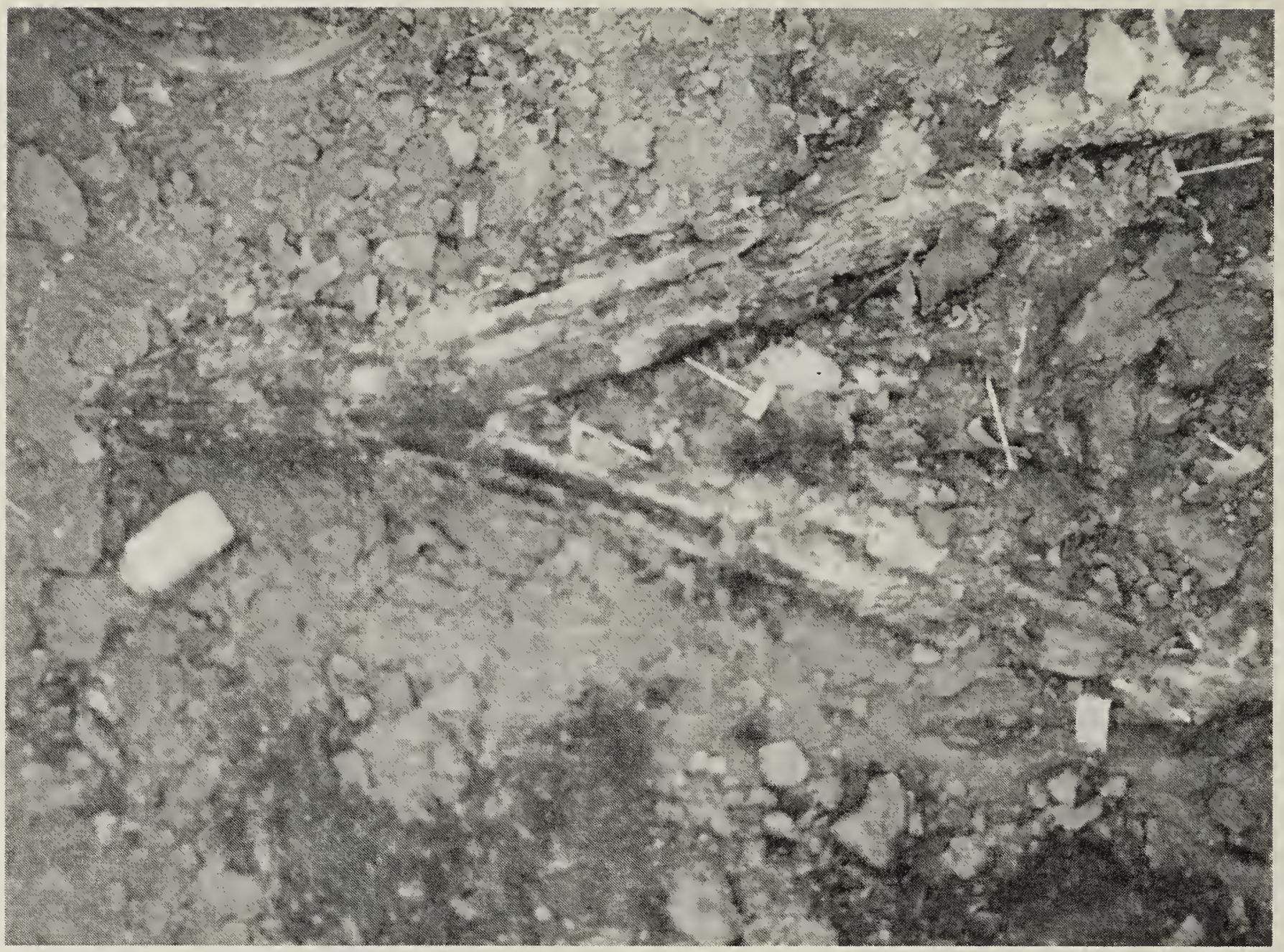

The skull, turned upside down, in the rock. This picture shows the "Y-shaped" lower jaw.

Tim Tokaryk

Natural History Society, the Saskatchewan Museum of Natural History (SMNH) and the Museum of Natural History associates, we were able to recover the endangered bones, and make a surprising discovery at the same time.

\section{The Excavation}

The excavation took eight days and involved three people, Frank McDougall, Doug Taylor and myself. We were prepared for bad weather, bringing a large floorless cook tent to cover a portion of the quarry. This came in handy on the second day when it snowed continuously. The snow also presented problems in getting to the quarry via grid roads and small trails, and made exposing the bone very difficult. Though the tent protected us somewhat from the cool wind and snow, the glue we were using would not harden at low temperatures. Our problem was solved when two propane heaters were sent up from Regina.
Our prime objective was to remove the bones near the edge of the cliff and collect anything else we could remove in the time that we had. We had to remove a couple of tonnes of shale which covered the find. This part of the job was slow because we had to examine every major piece of shale carefully, to collect other fossils that are abundant in the deposit. The method of splitting shale, examining, then either tossing or keeping blocks, turned up several shark teeth, a scattering of fish parts and two articulated fish skeletons.

The main specimen we were going to such lengths to collect was a partial, articulated skeleton. By the time we finished, our bone count was over 75 with more going into the hill. The largest bone was the skull, at $1.3 \mathrm{~m}$. After plastering, the block with the skull weighed over $160 \mathrm{~kg}$, and we had to face the problem of removing it. This was resolved by borrowing a four-wheeldrive all-terrain vehicle and a sled. After 
eight days we had collected over 100 bones and teeth from the quarry site.

\section{Am Not Sherlock Holmes}

Now I come to the detective work done at the site and back in the laboratory of the SMNH. It was my impression that the animal entombed in the black-grey shale was a marine reptile called a plesiosaur. There are two groups of these animals, the short-necked and long-necked, but generally these fisheaters had proportionally small heads, long necks, rotund bodies, large flippers and small tails. One kind of evidence I used in making my identification was that the only other large marine reptile known to have existed at this time, the mosasaurs, have vertebra centra that are convex/concave at the posterior and anterior ends. The Carrot River specimen has vertebra centra that are slightly concave/concave which are normally associated with plesiosaurs. Halfway through the excavation we found the skull with lower jaws attached; it was turned upside down. Though massive, the "Y-shaped" lower jaw could possibly have belonged to the shortnecked variety of plesiosaurs. Later we discovered the forelimb of an animal that was neither plesiosaur or mosasaur but had the general appearance of a land animal's leg. My imagination ran from the large, toothed birds to dinosaurs.

After our return to Regina, I began preparation of the limb, which turned out to be nearly complete from the shoulder girdle (scapula/coracoid) down to its finger bones (phalanges). The next stage of preparation began - the skull. The first area to be worked on was near the end of the snout where a large hole (external nares) was soon uncovered. Only one group of animals - crocodiles - has this feature. After this it was easy to put one and one together. What we thought were two animals, the plesiosaur and whatever, were in fact one large crocodile. [I am reminded of a quote from "The Adventures of Black Peter," a Sherlock Holmes tale: "We all learn by experience and your lesson this time is that you should never lose sight of the alternative.']

\section{Million Years Ago}

This crocodile lived 85 million years ago when portions of the interior of North America were under water, in what was called the Western Interior Seaway. We are certain of the aquatic nature of these sediments and this skeleton by the variety of fish and shark remains and by the fact that this particular group of crocodile is found only in marine sediments. We are also fairly confident in our estimation of the age through relative dating. This age determination will be further strengthened by radiometrical dating of the bentonite (volcanic ash) layers overlying the skeleton.

The skeleton, by rough comparisons with similar types found elsewhere, would have been about seven $m$ long. The crocodile probably fed on fish.

Crocodile records from marine rocks of North America during the Late Cretaceous Period are extremely rare. The group that I think this specimen belongs to, the sub-order Mesosuchia, family Pholidosauridae, is represented by only four or five specimens.

\section{The Future}

We left the site knowing that there are more bones in the hill. Whether we have a complete skeleton or not will not be known until next year when we return. There are many questions about life 85 million years ago in an area we now call the Carrot River, and with further study and collecting we may just be able to answer a few of them. 